\title{
Integrated Miniature Multiband Antenna Designed for WWD and SAR Assessment for Human Exposure
}

\author{
Brahim Fady $\mathbb{D}^{1},{ }^{1}$ Jaouad Terhzaz $\left(\mathbb{D},{ }^{2}\right.$ Abdelwahed Tribak $\left(\mathbb{D},{ }^{1}\right.$ and Fatima Riouch ${ }^{1}$ \\ ${ }^{1}$ Department of Microwave and Communication Antenna Subsystems, INPT, Rabat, Morocco \\ ${ }^{2}$ Department of Physics, CRMEF Casablanca Settat, Casablanca, Morocco \\ Correspondence should be addressed to Brahim Fady; brahim.fady@gmail.com
}

Received 21 January 2021; Revised 21 March 2021; Accepted 25 March 2021; Published 9 April 2021

Academic Editor: Giovanni Andrea Casula

Copyright (c) 2021 Brahim Fady et al. This is an open access article distributed under the Creative Commons Attribution License, which permits unrestricted use, distribution, and reproduction in any medium, provided the original work is properly cited.

The article introduces a new, low-cost, integrated, multiband antenna design intended for wristbands and wearable wireless devices (WWD). With a miniaturized planar square-shape sizing $29 \times 29 \mathrm{~mm}^{2}$, the antenna can fit easily inside WWDs. The proposed design covers the most used frequency bands such as LTE2300, ISM2400, LTE2600, WiMAX3500, WiMAX5200, and ISM5800 in which the antenna reaches up to $-25 \mathrm{~dB}$ and $6.9 \mathrm{dBi}$ in terms of $\mathrm{S} 11$ and gain, respectively. To evaluate the exposure amenability of design on human body, we studied the specific absorption rate (SAR) of the design in two main use cases: multilayered human wrist model and a SAM (Specific Anthropomorphic Mannequin) head model. In each use case, the SAR results in different positions for all frequencies are compared to FCC standards.

\section{Introduction}

Since 1999, wearable wireless devices such as smartwatches, bracelets, and smart glasses are becoming widely used in healthcare, industry, and mainly in everyday life [1]. Nowadays, the smartphones field experiences a strong competition with the evolution and the fast development of smartwatches and wearable devices. Thanks to these smart wearable products, the internet of things is becoming more and more concrete, reigning our daily life and thus shaping our regular tasks. The user, just by speaking to his watch, can control any type of smart object in his house, such as television, coffee machine, and even lighting lamps. In the other direction, these objects can also communicate with the user by providing information in real time or generating conditional events, as in the case of the monitoring cameras which can on the detection of an intruder send an alert with photo to the user through his smartwatch, smart glass, or any similar WWD.

The main challenge in smartwatch and WWD industry is the connectivity; their small structure requires miniature antennas that enable the required wireless technologies such as Wi-Fi, Bluetooth, LTE, and WiMAX. For this reason, studies and researches about smartwatches antennas are progressing recently. Wu et al. presented in [2] a multipleinput-multiple-output (MIMO) antenna design for a smartwatch in $5.2-5.8 \mathrm{GHz}$ wireless applications. The proposed MIMO design has shown excellent performance in the $\mathrm{Wi}$-Fi 5.2 and $5.8 \mathrm{GHz}$, but the other required technologies such as Wi-Fi $2.4 \mathrm{GHz}$, Bluetooth, and LTE are not covered, and the antenna must be embedded in the plastic watchstrap of the smartwatch presenting a constraint for the constructors. Another MIMO antenna that relies on the smartwatch structure is developed in [3], where Wen et al. designed a capacitive feed structure operating in $\mathrm{Wi}-\mathrm{Fi} /$ Bluetooth band. Such design is intended specifically for metal frame round smartwatch. In [4], a miniature printed inverted-F antenna sizing $15 \times 36 \times 0.3 \mathrm{~mm}^{3}$ is designed to cover the ISM band and proposed for IoT applications, but the antenna presents low gain and the other required bands for smartwatch use case are not covered, contrarily to the multiband suggested antenna in [5] but with bigger size. A slotted design with compact Substrate Integrated Waveguide (SIW) is suggested in [6] to cover the $5 \mathrm{G} 28 \mathrm{GHz}$ and $38 \mathrm{GHz}$ bands. The SIW design with a volume of $28.7 \times 30.8 \times 0.82 \mathrm{~mm}^{3}$ can fit perfectly the smartwatch; 
however, the antenna does not radiate in the other required bands. Miniature planar inverted F-antenna was designed by Jeevani et al. in [7] using genetic algorithm optimization to obtain the best feed and shorting pin positions. The antenna covers the Wi-Fi band but required bands such as LTE are missing. Niyamanon et al. proposed in [8] a dual-frequency circularly polarized patch antenna with slant strip line and L-shaped slot and truncated square aperture for operation in $2.5 \mathrm{GHz}$ and $5.8 \mathrm{Ghz}$, but the proposed antenna with a size of $40 \times 54 \times 1.6 \mathrm{~mm}^{3}$ is difficult to implement inside a smartwatch and the bands of LTE are not covered. In [9] Liu et al. suggested a low profile design operating only for LTE bands, whereas in [10] Wang and Yung designed a built-in antenna operating in GPS and ISM bands based on complex materials. Wang and Yan designed in [11] an annular ring which surrounds the framework of the smartwatch with two ports of excitation; this design is very convenient for smartwatch with circular structure but cannot be used for other shapes. A dual-polarized slot antenna is presented in [12]; the design exhibits excellent performance in terms of gain and S11 for ISM2400, LTE2300, and LTE2600 bands, but the suggested structure cannot fit inside the average smartwatch size since the design requires an artificial magnetic conductor surface to act as a reflector for the antenna.

The objective of this work is to design a miniaturized antenna, suitable for WWD integration and covering the required technologies in smartwatch industry such as LTE2300, ISM2400, LTE2600, WiMAX3500, WiMAX5200, and ISM5800. This research presents first the parametric study of the proposed antenna and the impact of the structure parameters against the performance in term of reflection coefficient. Further a detailed analysis is given for the measurements of gain, radiation pattern, and reflection coefficient using the fabricated antenna. Finally, the human body exposure is evaluated against the radiation of the proposed design in compliance with FCC standards, using SAM Head model for SAR evaluation at mouth level for the use case where the user get the smartwatch close to his mouth to speak through it, and a multilayer model of human wrist. In each configuration we evaluate the SAR results at different positions for each frequency.

\section{Specification and Use Case}

2.1. Wearable Wireless Devices Evolution and Use Cases. Smartwatches are some of the most intimate and personal technology products available on the market. They are literally tied to their users with a strap and kept on the person almost all day, everyday. For many purposes, a smartwatch serves as a front end for a remote system such as a smartphone, communicating with the smartphone using various wireless technologies. Smartwatches in their typical forms shown in Figure 1 are advancing, especially their design, battery capacity, and health-related applications.

While internal hardware varies, most have an electronic visual display, either backlit LCD or OLED or Hologram [5]. Some use transflective or electronic paper, to consume less power. They are generally powered by a rechargeable lithium-ion battery. Peripheral devices may include digital cameras, thermometers, accelerometers, pedometers, heart rate monitors, altimeters, barometers, compasses, GPS receivers, tiny speakers, and microSD cards, which are recognized as storage devices by many other kinds of computers. Software may include digital maps, schedulers and personal organizers, calculators, and various kinds of watch faces.

These intimate devices pose a number of design challenges especially with regards to wireless transmission. First of all, the antenna must not contain active component to reduce power consumption. The antenna must be miniaturized as possible to fit inside the device. As shown in Figure 2 , the smartwatch may communicate with external devices such as sensors, wireless headsets, or a heads-up display, and just like other smart devices, a smartwatch may collect information from internal or external sensors and it may control, or retrieve data from, other instruments or computers [5]. The following technologies are necessary and sufficient to ensure the connectivity requirement of smartwatch industry: LTE2300, WiMAX3500, ISM2400, LTE2600, WiMAX5200, and ISM5800.

2.2. Antenna Requirement. In order to satisfy the smartwatch use case, we aim to design a planar antenna easy to implement inside the smartwatch case and cost effective for manufacturing. For cost optimization, the monolayer FR4 substrate is selected. According to smartwatch industry standards, e.g., Apple watch Series 6, the thickness of the smartwatch is between $7 \mathrm{~mm}$ and $10.5 \mathrm{~mm}$ and the PCB of the smartwatch processing unit is up to $1.6 \mathrm{~mm}$ of thickness. This means that we should use a substrate with a thickness of $0.8 \mathrm{~mm}$ to ensure that the antenna can fit perfectly inside the smartwatch. The average surface of the smartwatches is $40 \times 40 \mathrm{~mm}^{2}$ which constrains the antenna design that should be smaller. In terms of connectivity, we seek to cover most required wireless technologies to ensure wide usage of the antenna. The most used frequency bands are required for such application, listed in Table 1.

As shown in Table 1, we selected for the LTE technology 2 bands LTE2300 and LTE2600 serving for 4G communication. The Wi-Fi, Zigbee, and Bluetooth will be covered with the ISM2400 and ISM5800 bands, which can enable the Internet of Things communication, e.g., controlling smart speakers via Bluetooth. The WiMAX bands $3.5 \mathrm{GHz}$ and $5.2 \mathrm{GHz}$ can be used as an alternative of LTE for $4 \mathrm{G}$ and as an alternative to $\mathrm{Wi}-\mathrm{Fi}$ for long distance communication; e.g., in industrial IoT an operator can receive alerts from machines in his smartwatch.

\section{Antenna Design and Configuration}

3.1. Configuration and Parametric Study. The conception of the antenna is initiated with a planar microstrip structure. We designed each radiating element based on the wavelength derived from the target band. The length of the antenna elements is a factor of wavelength corresponding to each frequency band. The slots in the ground plane help 


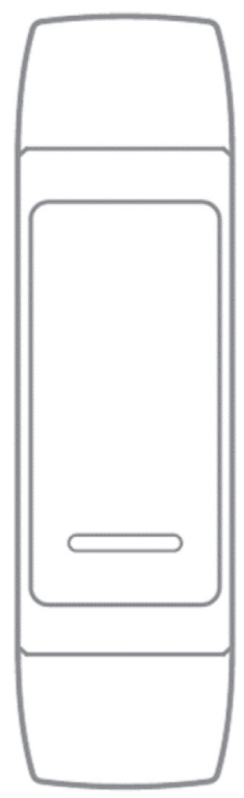

(a)

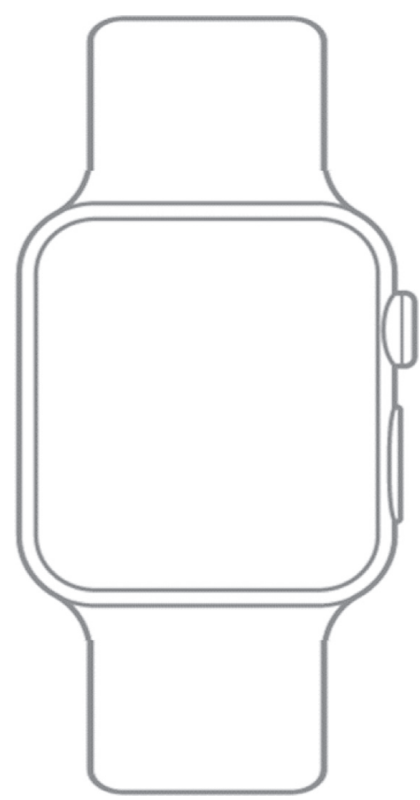

(b)

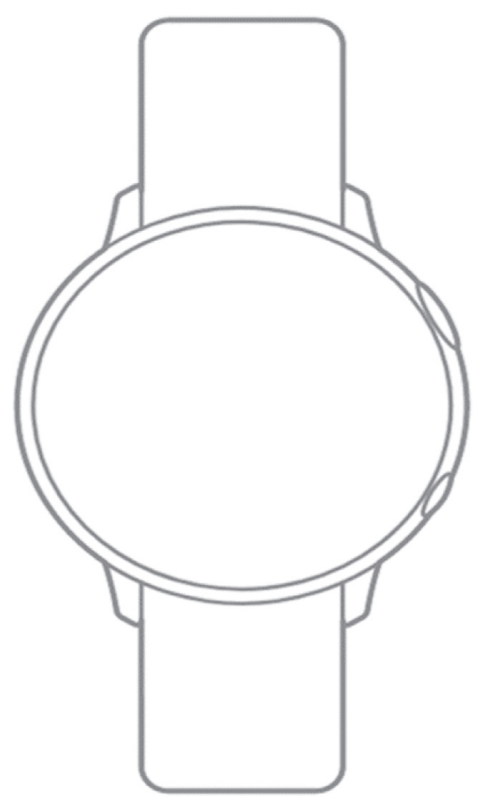

(c)

FIGURE 1: Smartwatch typical structures: (a) bracelet, (b) rectangular, and (c) round [13].

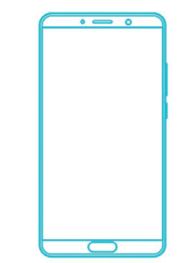

Smartphones

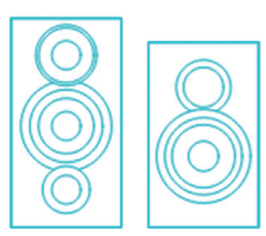

Smart speakers

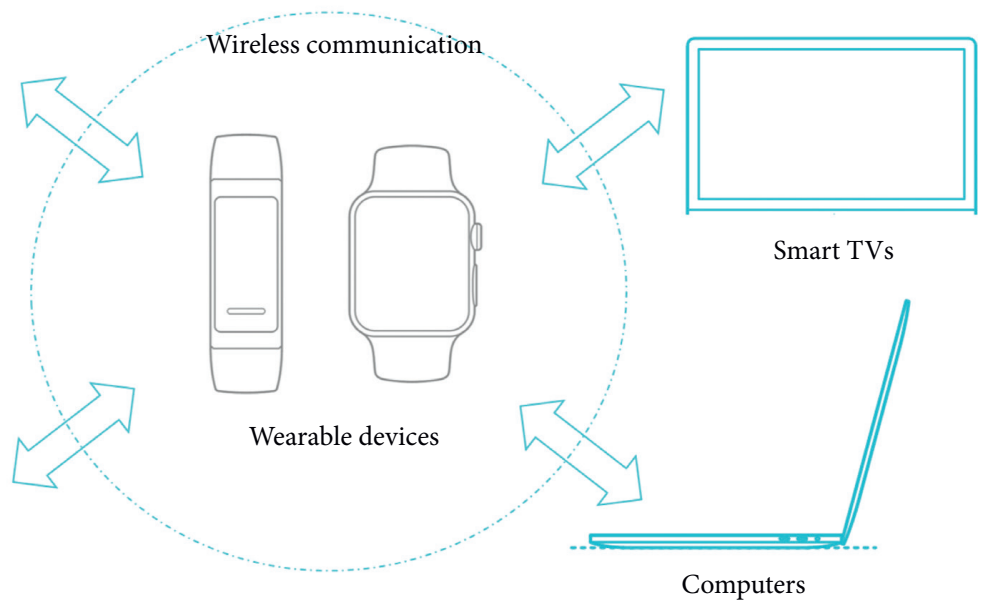

FIgURE 2: Smartwatch for IoT enabling.

TABLe 1: Frequency specification of the antenna design [5].

\begin{tabular}{lcc}
\hline Frequency $(\mathrm{GHz})$ & Bandwidth $(\mathrm{MHz})$ & Designation \\
\hline 2.3 & $2305-2400$ & LTE2300 band \\
2.4 & $2400-2500$ & ISM band \\
2.6 & $2500-2690$ & LTE2600 band \\
3.5 & $3500-3600$ & WiMAX3500 band \\
5.2 & $5200-5300$ & WIMAX5200 band \\
5.8 & $5750-5850$ & ISM5800 band \\
\hline
\end{tabular}

achieve the target bands as well as the coupling between the radiating items. In each phase of the conception, the current distribution is assessed in several iterations to make the convenient adjustments on the size of the element influencing the target band. The antenna was designed and optimized with the software CST Studio Suite ${ }^{\circledR}$ electromagnetic field simulator.

The reflection coefficient results over the frequencies are presented in Figure 3(a). From the results obtained, all the target frequencies are covered with $S 11$ variating from $-7 \mathrm{~dB}$ 


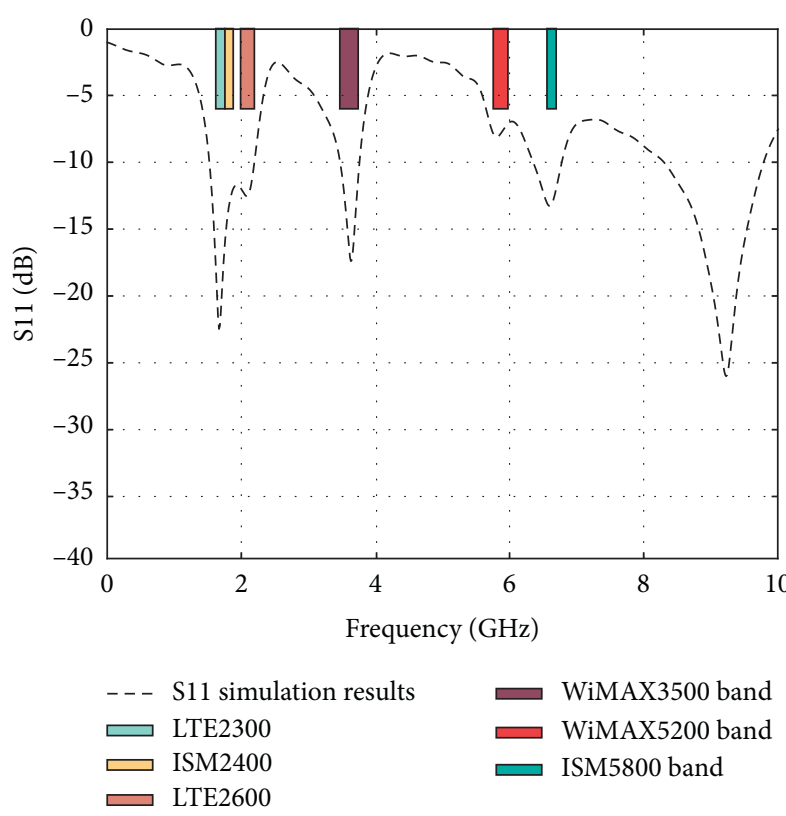

(a)

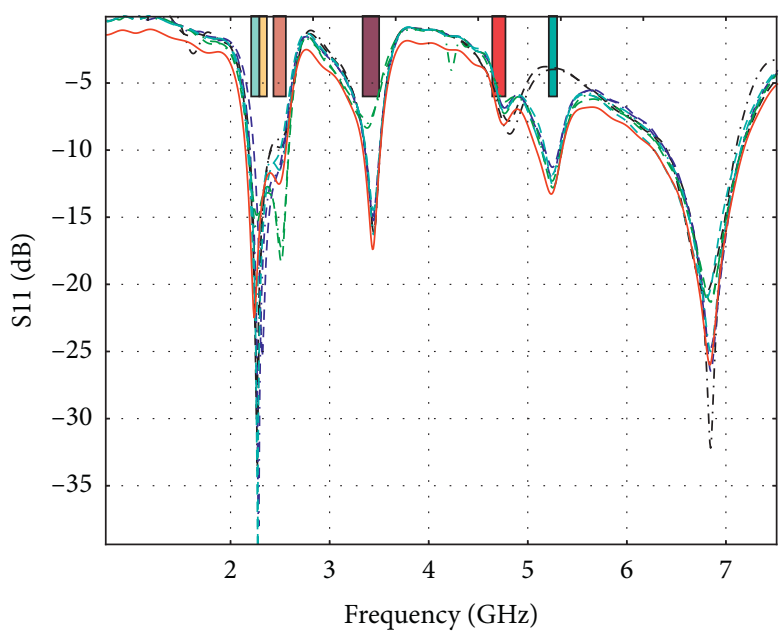

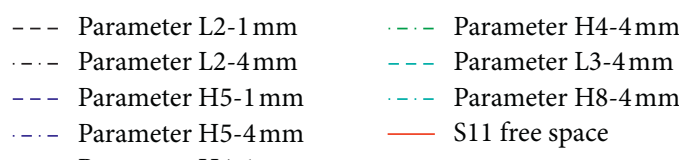

- - - Parameter H4-1 mm

(b)

FIGURE 3: (a) S11 simulation results of each configuration. (b) Influence of antenna parameters on S11 simulation results.

obtained in the WiMAX5200 band to $-23 \mathrm{db}$, obtained in the LTE2300 band.

Figure 3(b) presents the influence of each antenna parameter on the S11 results. It is noticeable that the parameter L2 impacts the ISM5800 and LTE2600 bands, and the parameter H4 impacts mainly the WiMAX3500 band, whereas the other parameters are cross influencing the S11 in all the bands.

3.2. Final Design. The geometry of the proposed antenna design is presented in Figure 4. The planar structure is based on FR4 substrate, $0.8 \mathrm{~mm}$ thick, and having a constant dielectric of 4.3 and loss tangent of 0.002 . The antenna uses a fed line sizing $2 \times 14.5 \mathrm{~mm}^{2}$ and has a global size of $29 \times 29 \times 0.8 \mathrm{~mm}^{3}$. The antenna design is based on $16 \mathrm{pa}-$ rameters shown in Figure 4 and listed in Table 2.

\section{Results and Discussion}

4.1. Antenna Fabrication. We manufactured the proposed design shown in Figure 5, with the LPKF ProtoLaser S machine. This machine selectively removes the conductive layer made of copper for the FR4 substrate used for this design. To ensure a high-quality design, the machine traces the isolation channels with the laser to precisely create the intended design tracks and surfaces.

4.2. Measurement Configuration. As shown in Figure 6(b), the measurements of the reflection coefficient are performed with the Vector Network Analyzer (VNA) Agilent N3383 operating from $0.0003 \mathrm{GHz}$ to $9 \mathrm{GHz}$ with the Keysight cables. Before each measurement iteration, we used the Agilent 85033E $3.5 \mathrm{~mm}$ Calibration Tool Kit. As shown in
Figure 6(a), the radiation pattern measurements are evaluated using a Double-Ridged TEM Horn Antenna with the GEOZONDAS equipment Lens GZ0226DRH operating from 1 to $26 \mathrm{GHz}$.

As main measurement instrument, the digital sampling converter is used. Its characteristics are optimized according to the system's parameters. The Ultrashort-Pulse Electrical Generator serves as a measurement signal source.

4.3. Reflection Coefficient Measurements. The S-parameters in term of S11 of the proposed antenna connected to the smartwatch model are measured using the Agilent VNA where the results are presented in Figure 7 and compared to simulation results performed with CST Studio. For each measurement iteration, Port 1 of the VNA is excited and the other ports are looped with a $50 \Omega$ load. As shown in Figure 7 , the measurements approve the simulations results for all target frequency bands. We notice better values of the S11 of the measurement in comparison to the simulation up to $-10 \mathrm{~dB}$, for frequencies higher than $4 \mathrm{GHz}$. Based on the results obtained, all the required frequency bands are covered giving a large bandwidth of $700 \mathrm{MHz}$ and an S11 up to $-25 \mathrm{~dB}$ for LTE2300, ISM2400, and LTE2600 bands and $400 \mathrm{MHz}$ bandwidth with an S11 up to $-23 \mathrm{~dB}$ for WiMAX3500. The results show a wide band covering the WiMAX5200 and ISM5800 with a bandwidth up to $3200 \mathrm{MHz}$ and S11 up to $-17 \mathrm{~dB}$.

4.4. Radiation Results. Figures 8 and 9 show the measured radiation pattern depicted in two dimensions for Elevation and Azimuth plot, respectively, and performed for each frequency according the to the configuration presented in Figure 6. 


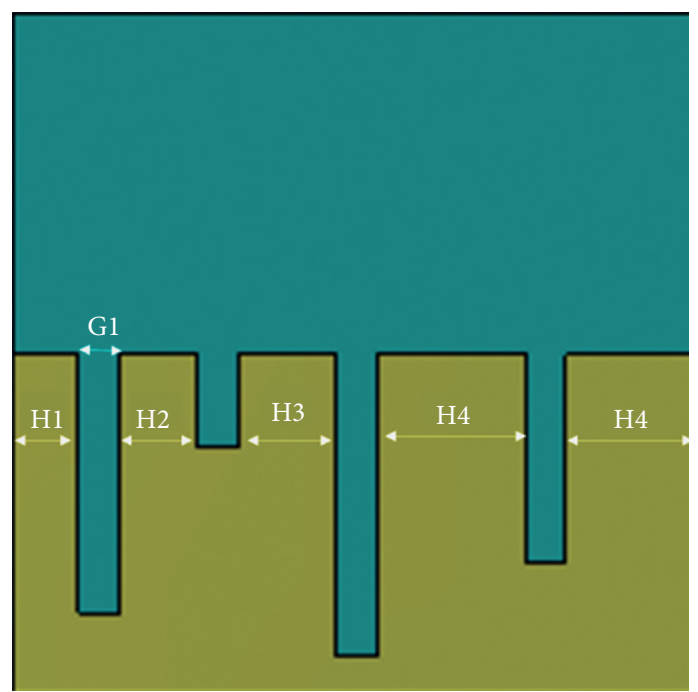

(a)

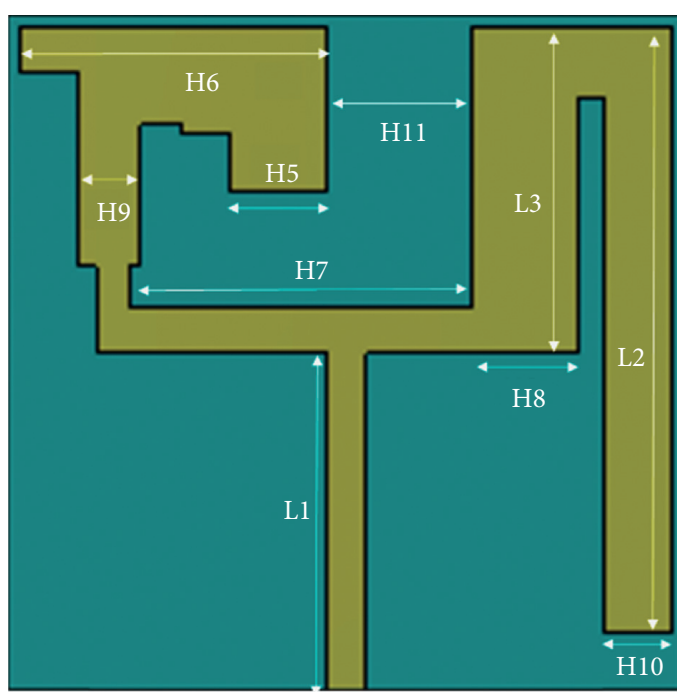

(b)

Figure 4: Proposed design geometry: (a) bottom and (b) top.

TABLE 2: Dimensions of the proposed antenna.

\begin{tabular}{lc}
\hline Parameter & Value $(\mathrm{mm})$ \\
\hline H & 29 \\
W & 29 \\
L1 & 6.6 \\
L2 & 21 \\
L3 & 4 \\
H1 & 2.7 \\
H2 & 3.27 \\
H3 & 4.17 \\
H4 & 6.26 \\
H5 & 4.2 \\
H6 & 13.2 \\
H7 & 14.7 \\
H8 & 4.6 \\
H9 & 2.67 \\
H10 & 3 \\
G1 & 1.73 \\
\hline
\end{tabular}

Based on the measurement results presented in Figures 8 and 9, we notice that the proposed design is quasiomnidirectional for the frequency bands LTE2300 and WiMAX3500 with a maximum gain up to $6.9 \mathrm{dBi}$ and $6.5 \mathrm{dBi}$, respectively, whereas it is noticeable that the antenna is near omnidirectional for frequency bands ISM2400, LTE2600, WiMAX5200, and ISM5800 with a maximum gain up to $6.9 \mathrm{dBi}$.

The maximum gain over frequencies is presented in Figure 10. The measurement results show that the maximum gain varies slightly over the target frequency bands. The maximum variation is $7.8 \%$ corresponding to difference between the lowest value $6.4 \mathrm{dBi}$ at $3.5 \mathrm{GHz}$ to the highest value $6.9 \mathrm{dBi}$ at $5.8 \mathrm{GHz}$.

4.5. Current Distribution. The current distribution results are shown in Figure 11 as per the frequency scope. In each frequency, different area in the antenna structure is involved with relevant density.
4.6. Total Efficiency. In Figure 12, we present the variation of the total efficiency as a function of the frequency. The results obtained show that the antenna radiates at least $70 \%$ of the signal in the majority of cases, except for the WiMAX5200 band where the total efficiency is around $50 \%$.

4.7. Influence of the Smartwatch. The influence of the smartwatch case on antenna reflection coefficient is assessed for different configuration. As shown in Figure 13, we used a plastic case as alternative to smartwatch box case and attached the antenna to the case using a tape. The S11 of the antenna with the tape only is measured first to assess the impact of the tape; then, the antenna is attached to the smartwatch case with a separation of $1 \mathrm{~mm}$ to investigate the smartwatch case impact on the S11. Afterward we mounted the antenna with the case on human hand to assess the variation of the S11 in two configurations: antenna with a separation of $1 \mathrm{~mm}$ to the case and antenna without separation to the smartwatch case.

The measurement results of the reflection coefficient for each configuration are presented in Figure 14. The obtained results show that the plastic tape used to attach the antenna to the smartwatch case has no impact on the S11 results. When the antenna is attached to the case with $1 \mathrm{~mm}$ separation, the S11 magnitude and bandwidth values are the same as results obtained in the free space for frequencies lower than $4 \mathrm{GHz}$. Notwithstanding, we notice a bandwidth $400 \mathrm{MHz}(10 \%)$ lower than the free space results between $4 \mathrm{GHz}$ and $9 \mathrm{GHz}$, but the $\mathrm{S} 11$ value is lower for the WiMAX5200 with a decrease up to $-24 \mathrm{~dB}$ than the free space results. When the system antenna and case are mounted on the human hand, the only significant variation is obtained for the ISM5800 band, where the S11 is increased from $-30 \mathrm{~dB}$ to $-15 \mathrm{~dB}$ without impact on the bandwidth.

It is noticeable that removing the separation between the antenna and the case induces a variation in the S11 


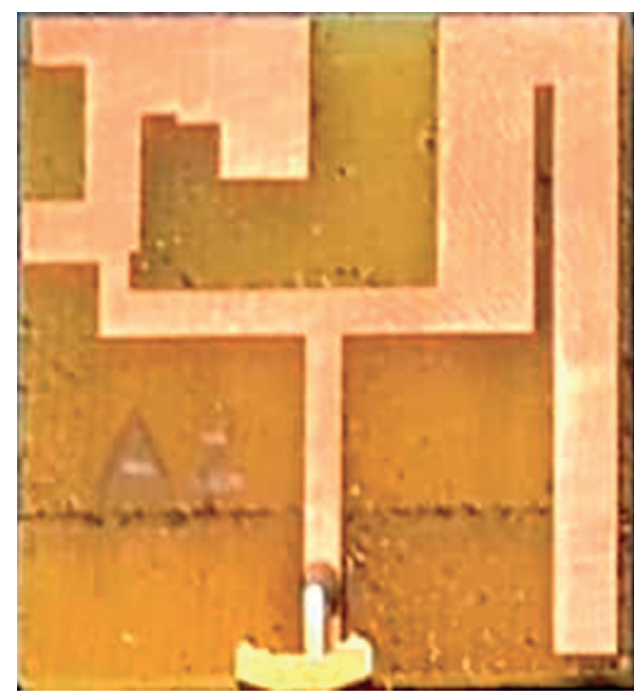

(a)

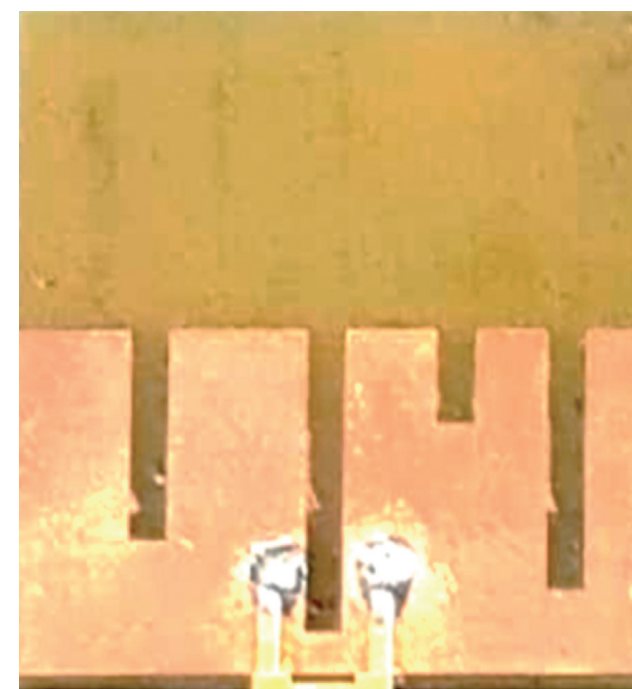

(b)

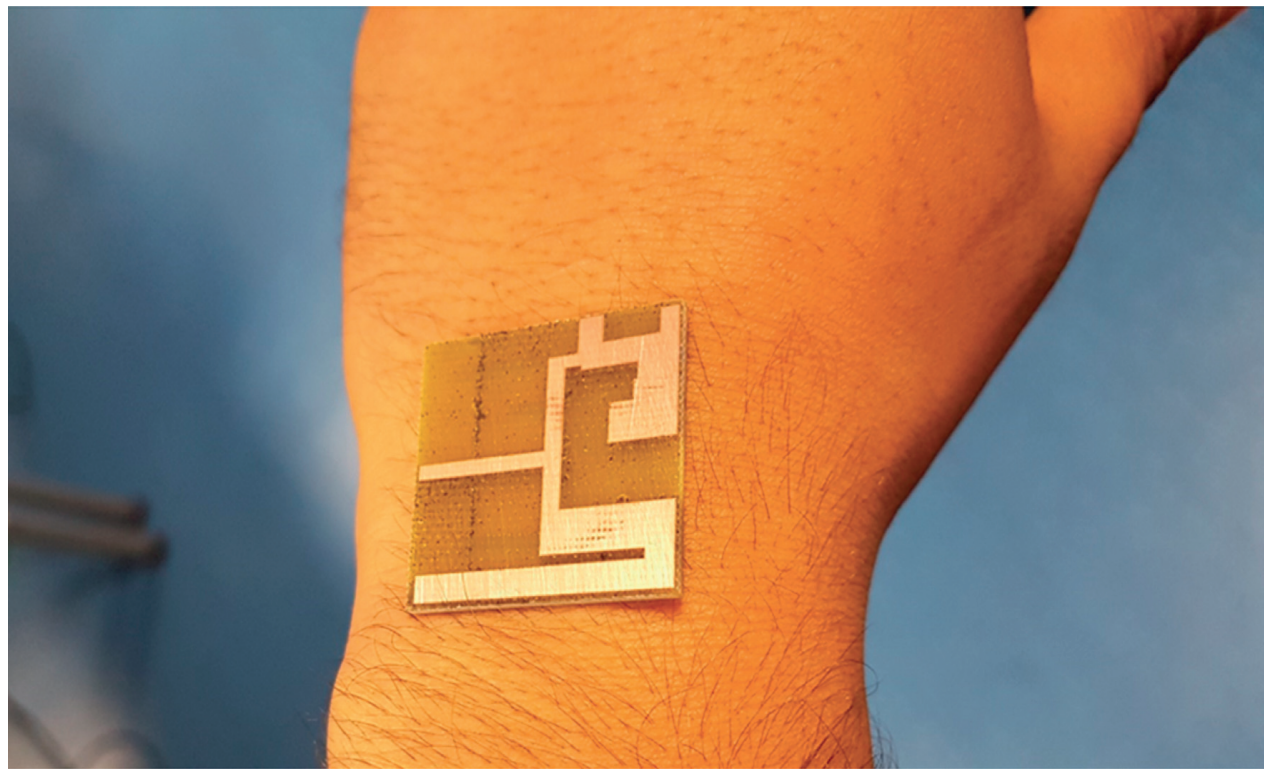

(c)

Figure 5: Manufactured antenna design.

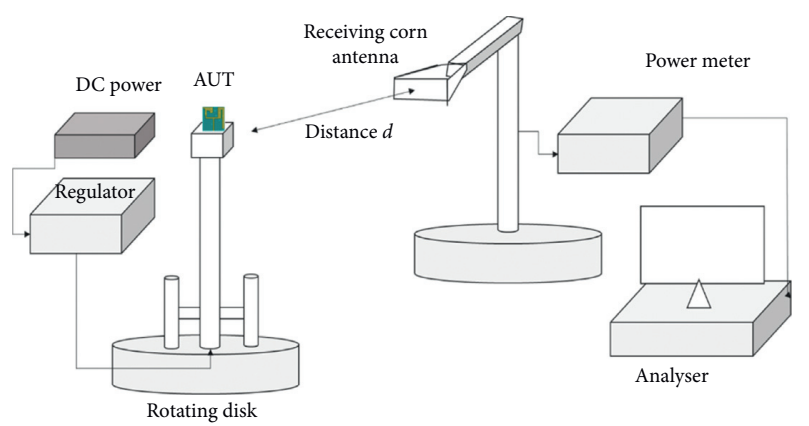

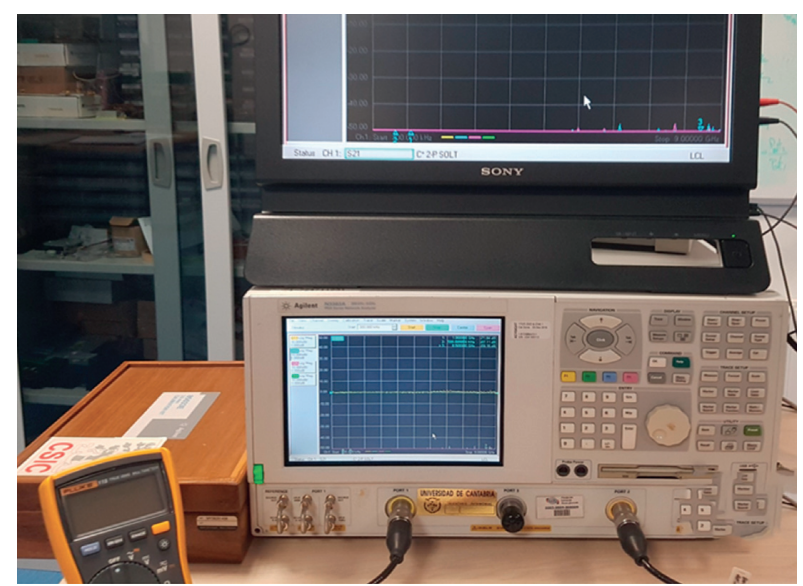

(b)

FIgURE 6: Measurement configuration: (a) gain and radiation pattern [5] and (b) reflection coefficient. 


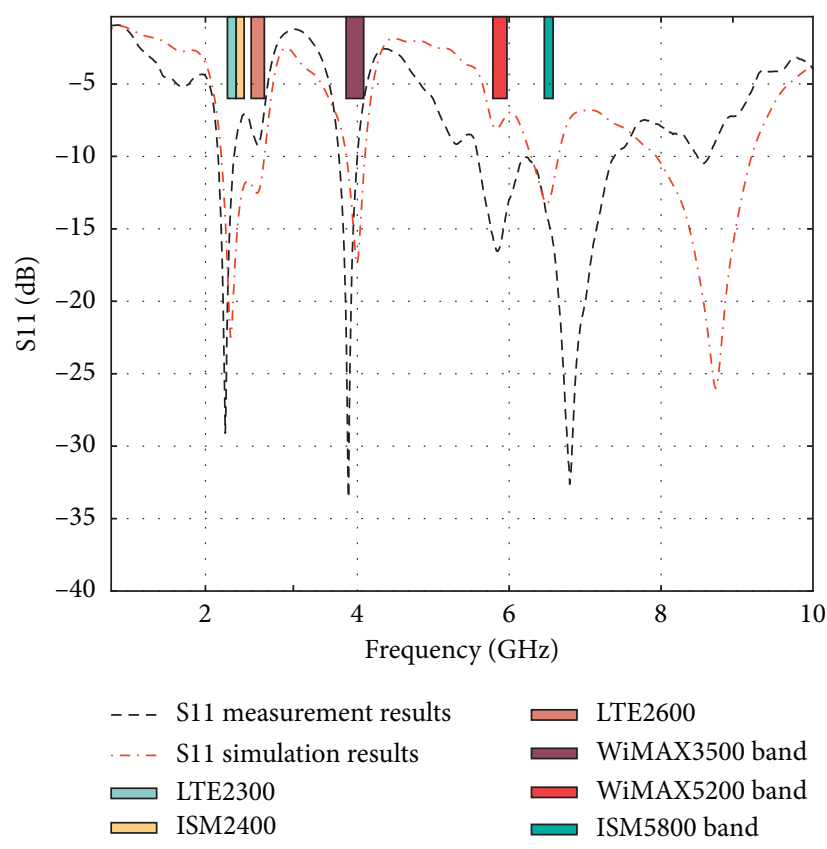

Figure 7: $S_{11}$ measurements results compared to simulations.

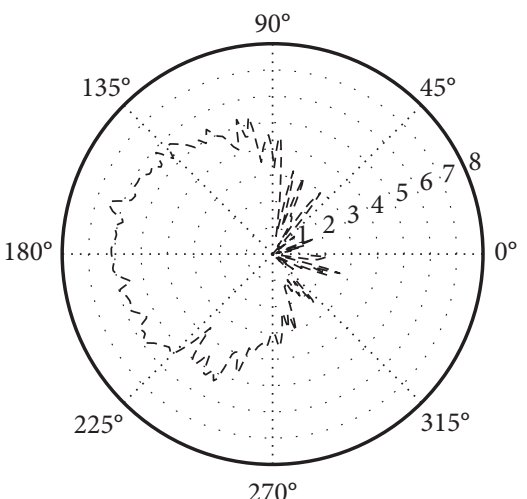

(a)

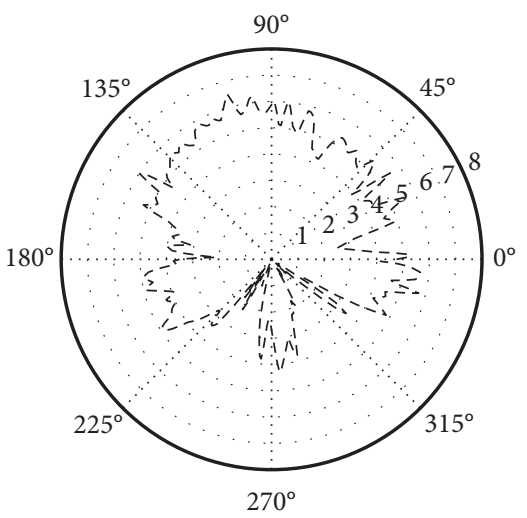

(d)

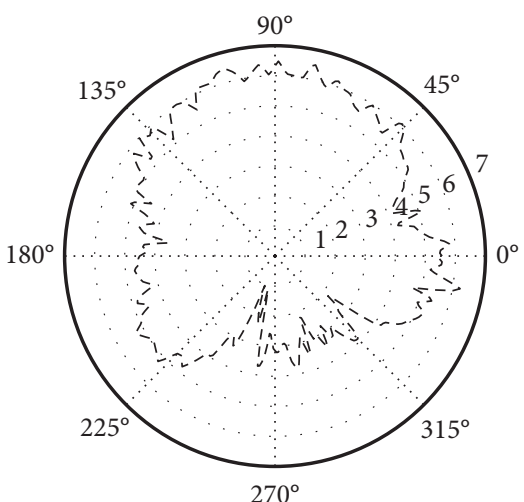

(b)

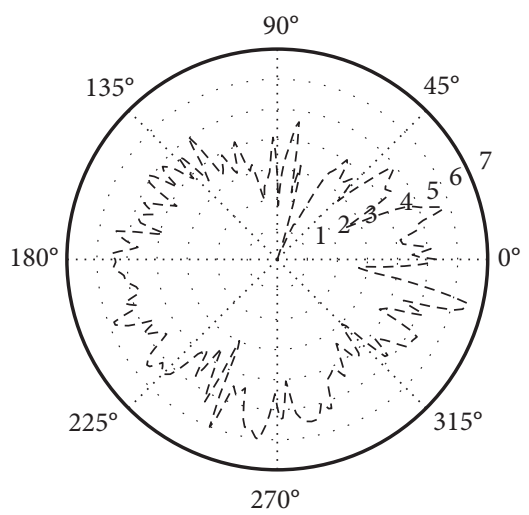

(e)

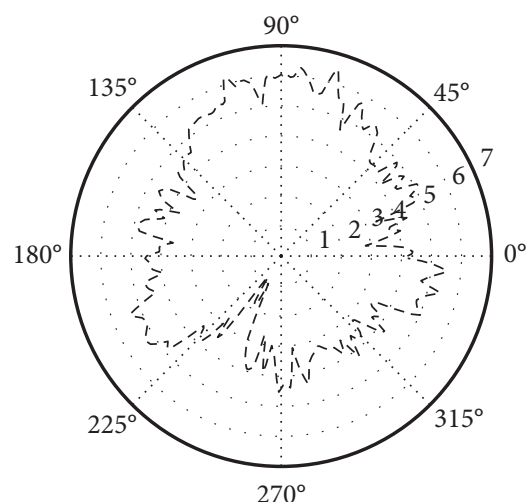

(c)

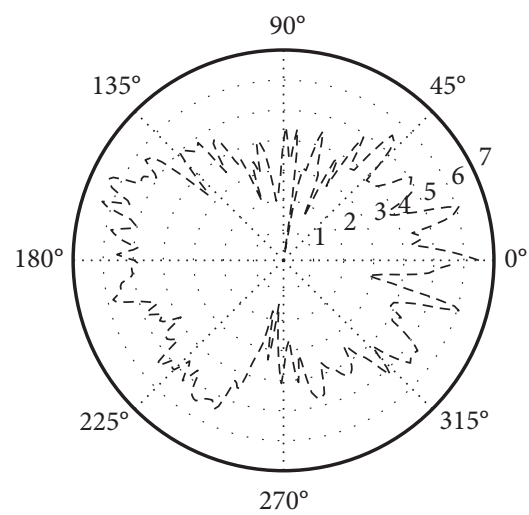

(f)

Figure 8: Elevation view of the radiation pattern: (a) $2.3 \mathrm{GHz}$, (b) $2.4 \mathrm{GHz}$, (c) $2.6 \mathrm{GHz}$, (d) $3.5 \mathrm{GHz}$, (e) $5.2 \mathrm{GHz}$, and (f) $5.8 \mathrm{GHz}$.

magnitude for frequencies higher than $5 \mathrm{GHz}$ with an average increase of the $\mathrm{S} 11$ up to $-8 \mathrm{~dB}$ compared to results obtained with $1 \mathrm{~mm}$ separation. For the frequencies lower than $5 \mathrm{GHz}$, the results are slightly better for LTE2600 and
ISM2400 bands where the S11 is $4 \mathrm{~dB}$ lower than the results obtained at a separation of $1 \mathrm{~m}$. The measurements confirm that the target bands are covered in all the configurations and for both separation 1 and $0 \mathrm{~mm}$. 


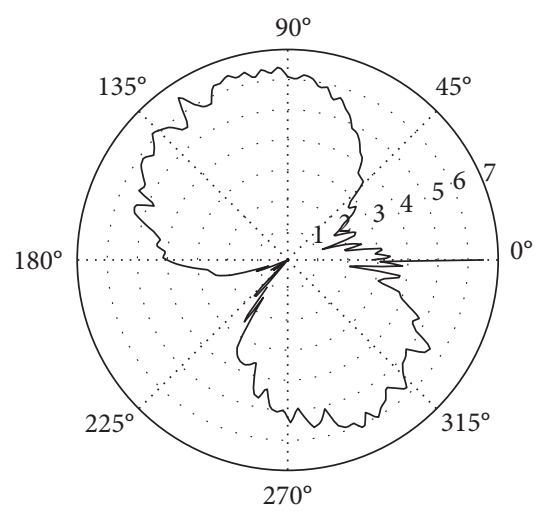

(a)

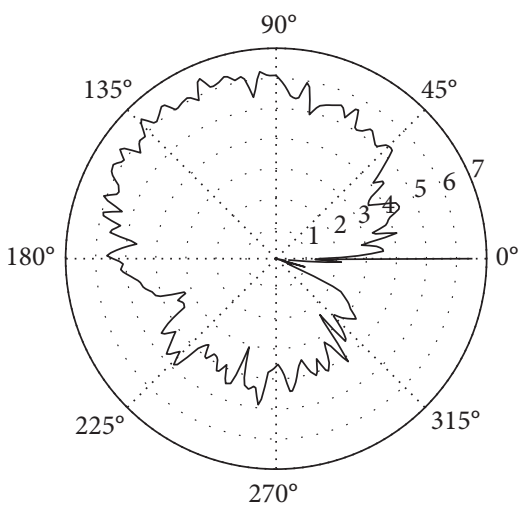

(d)

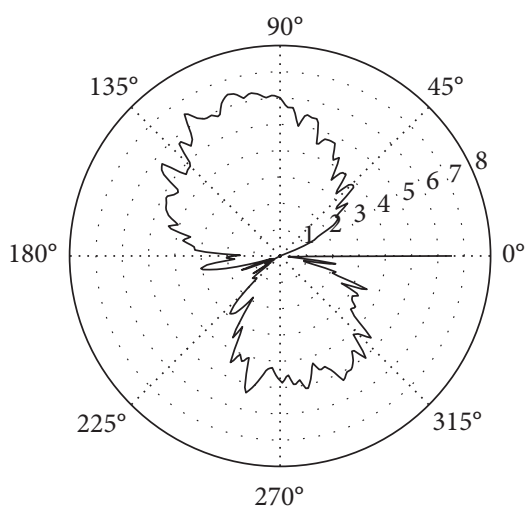

(b)

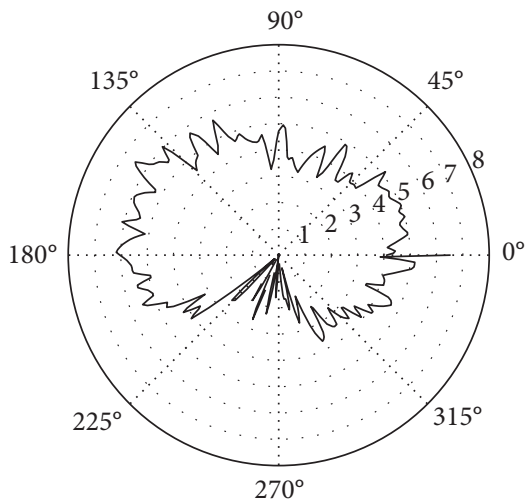

(e)

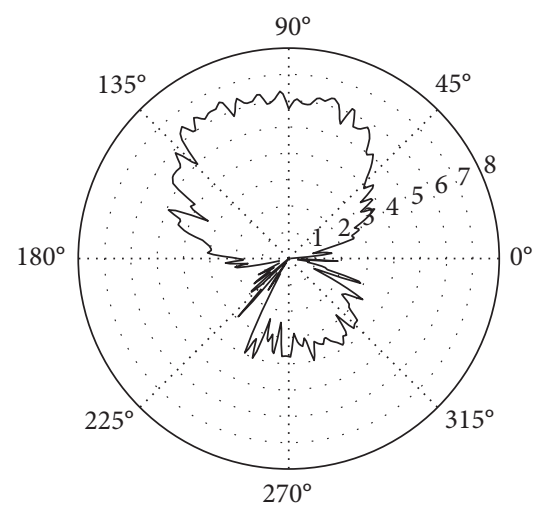

(c)

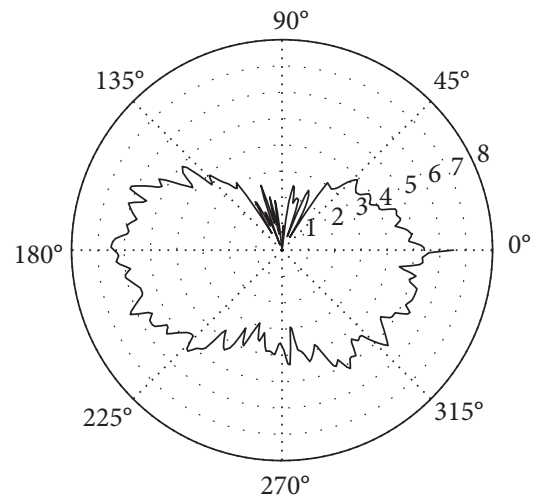

(f)

Figure 9: Azimuth view of the radiation pattern: (a) $2.3 \mathrm{GHz}$, (b) $2.4 \mathrm{GHz}$, (c) $2.6 \mathrm{GHz}$, (d) $3.5 \mathrm{GHz}$, (e) $5.2 \mathrm{GHz}$, and (f) $5.8 \mathrm{GHz}$.

\section{Comparison to State-of-the-Art Designs}

The proposed design is compared with the state-of-the-art designs in the same research area and results are summarized in Table 3. Overall, the proposed design exhibits better advantages over other antennas in terms of miniature size, covered bands, and maximum gain. Thanks to its miniature size and planar shape, the proposed design is a competitive candidate for both rectangular and round structures of smartwatches.

\section{SAR Studies}

In order to assess the human exposure to the proposed antenna radiation, the SAR performance of the antenna is evaluated in two configurations. The first configuration consists of mounting the antenna on the human hand wrist whereas we place the antenna next to SAM head mouth in the second configuration which illustrates the speaking mode through smartwatch. The results of SAR evaluation are verified against the SAR value limits required by the FCC standard, which are $2 \mathrm{~W} / \mathrm{kg}$ averaged over $10 \mathrm{~g}$ and $4 \mathrm{~W} / \mathrm{kg}$ averaged over $10 \mathrm{~g}$ of tissue of human head and hand wrist, respectively [15-21].

6.1. Antenna on Hand Wrist. The configuration of the antenna mounted on the human hand wrist model is shown in
Figure 15. The figure shows also the four layers of human wrist tissue. Four antenna to wrist separations are selected to evaluate the SAR results: $d=1 \mathrm{~mm}, d=2 \mathrm{~mm}, d=4 \mathrm{~mm}$, and $d=7 \mathrm{~mm}$. For each separation, the SAR is calculated for each frequency band required within the scope of this research.

The presented wrist model consists of a three-dimensional human hand model with four tissue layers: skin, fat, muscle, and bone. The dielectric properties of each layer are listed in Table 4 as well as the conductivity for each frequency.

Table 5 explores the maximum SAR results averaged over a mass of $10 \mathrm{~g}$ of hand wrist tissue, for each separation, frequency band, and tissue layer. The results presented in Table 5 show that the maximum SAR values obtained in each layer of the hand wrist tissue are lower than $4 \mathrm{~W} / \mathrm{kg}$ and thus meet the SAR limits defined by the FCC Standards. Since the dielectric properties of the fat tissue are lower than the dielectric properties of the skin tissue, it is worthy to note that even though the fat layer is below the skin layer, the maximum SAR results obtained in the fat layer are slightly high (up to $0.009 \mathrm{~W} / \mathrm{kg}$ ) for each antenna to wrist separation and at each frequency band. We also notice that the maximum SAR results decrease up to $45 \%$ from the fat tissue down to muscle tissue and similarly from the muscle tissue down to bone tissue up to $64 \%$, whereas from frequency perspective we observe that the maximum SAR results in ISO-tissue level 


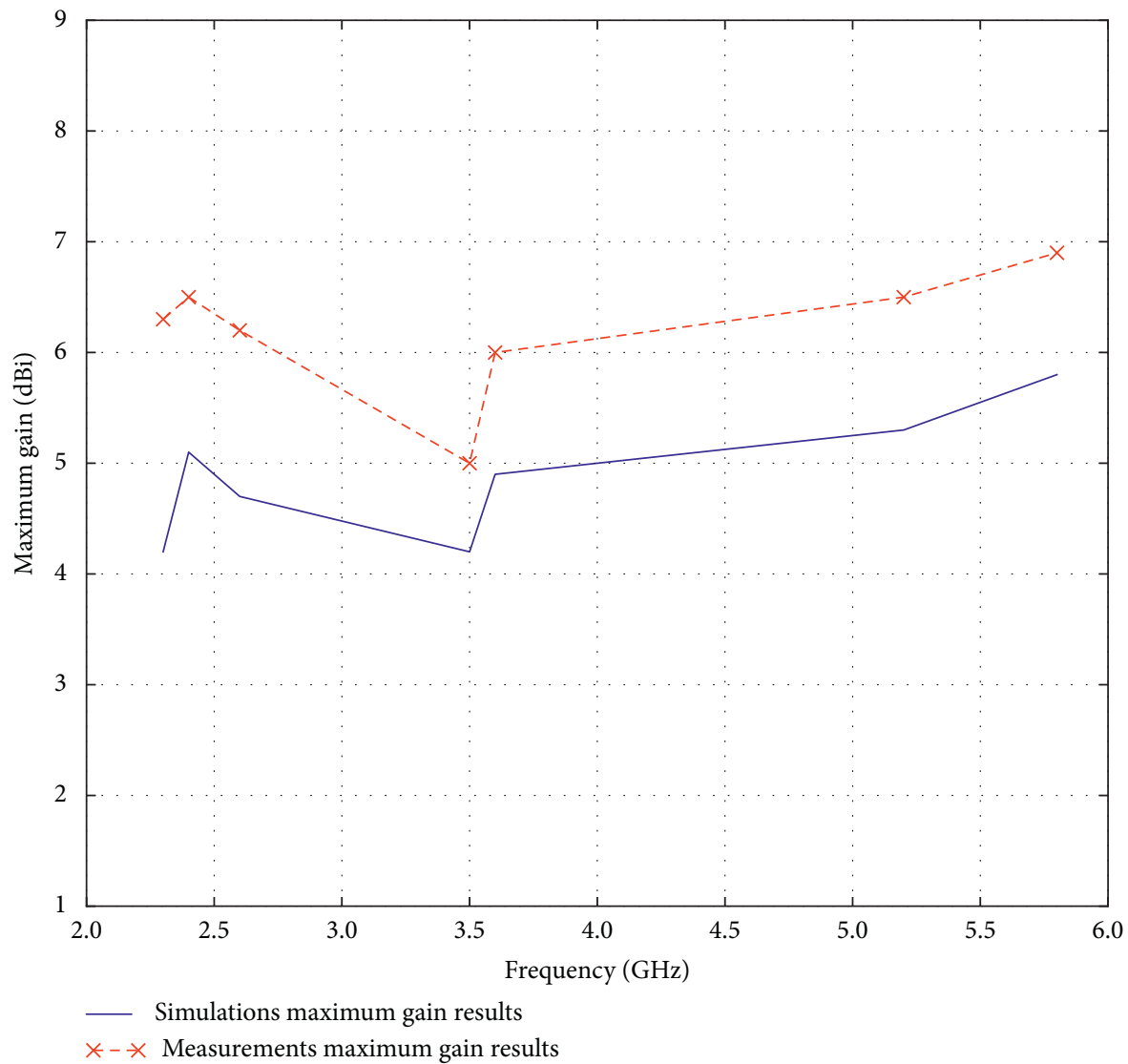

Figure 10: Variation of the maximum gain over frequencies.

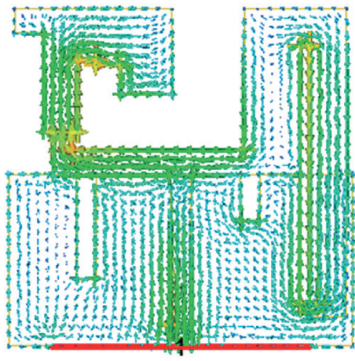

(a)

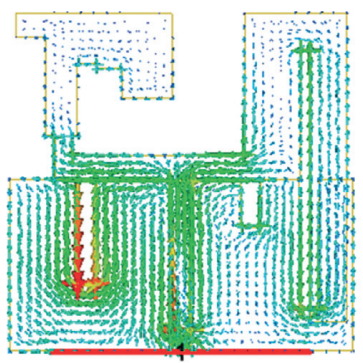

(d)
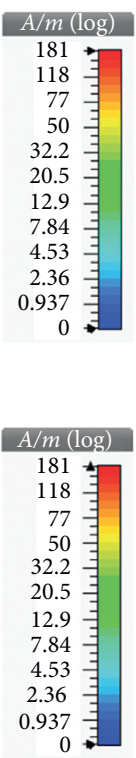

0

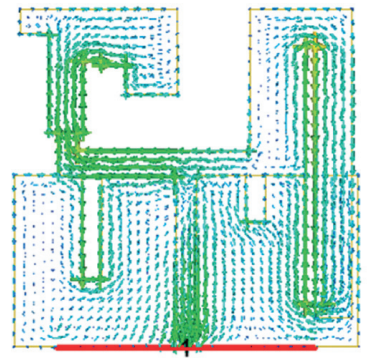

(b)

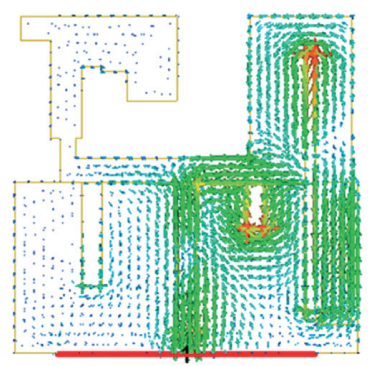

(e)
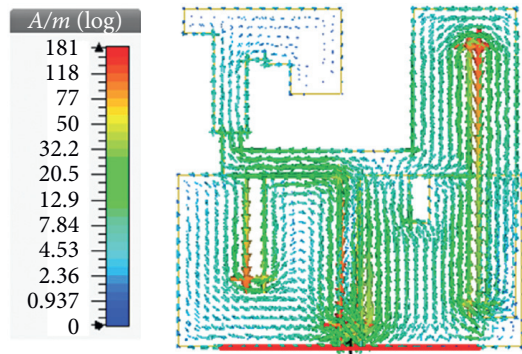

(c)

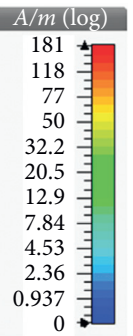

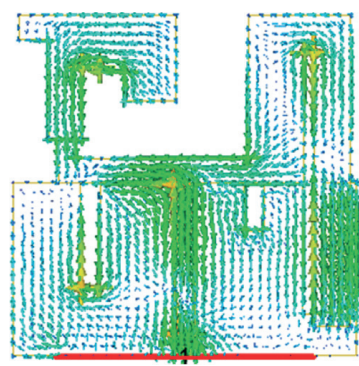

(f)
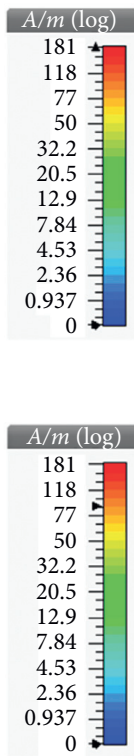

0 :

Figure 11: Current distribution per frequency: (a) $2.3 \mathrm{GHz}$, (b) $2.4 \mathrm{GHz}$, (c) $2.6 \mathrm{GHz}$, (d) $3.5 \mathrm{GHz}$, (e) $5.2 \mathrm{GHz}$, and (f) $5.8 \mathrm{GHz}$. 


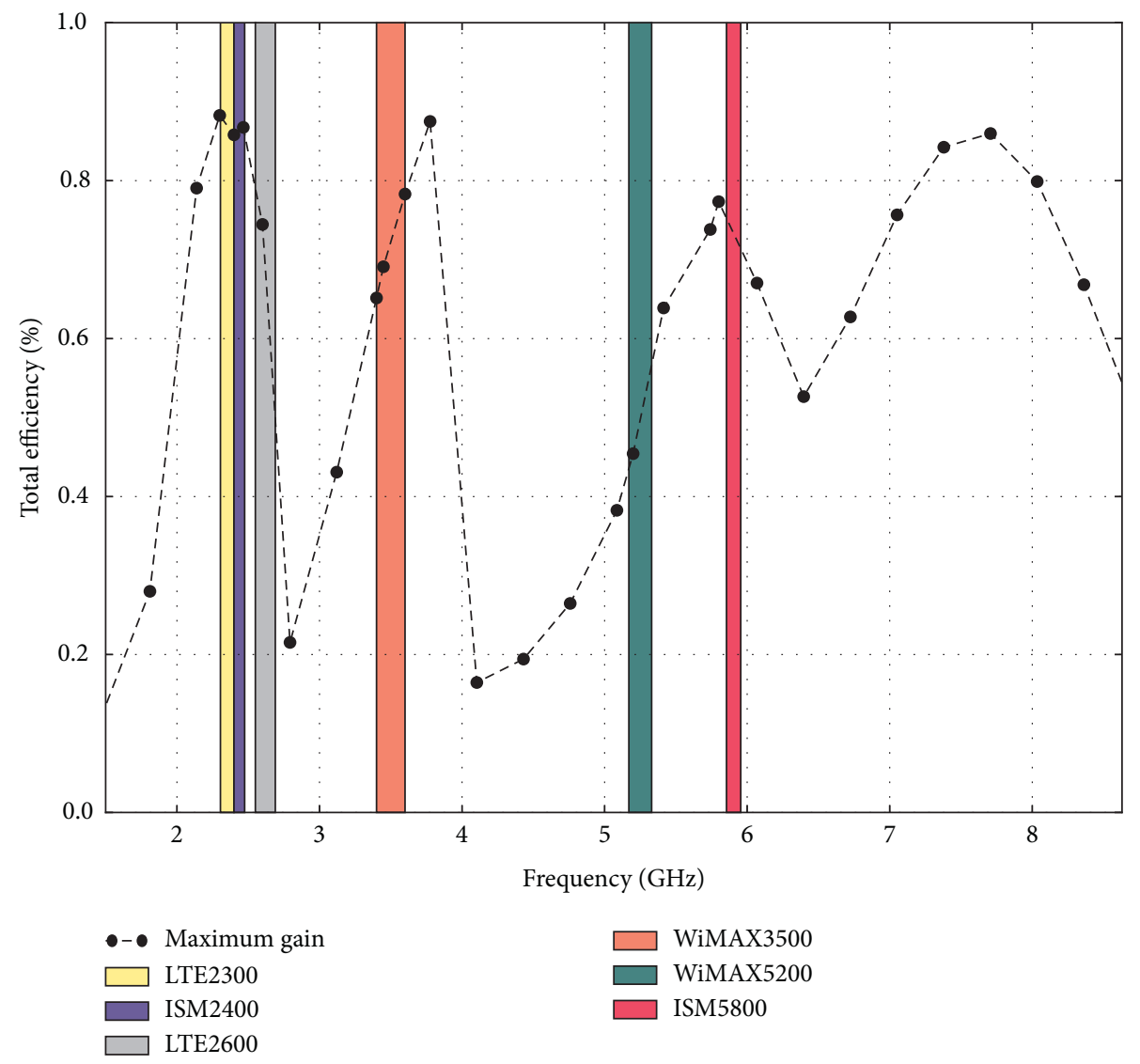

FIgURE 12: Variation of the total efficiency over frequencies.

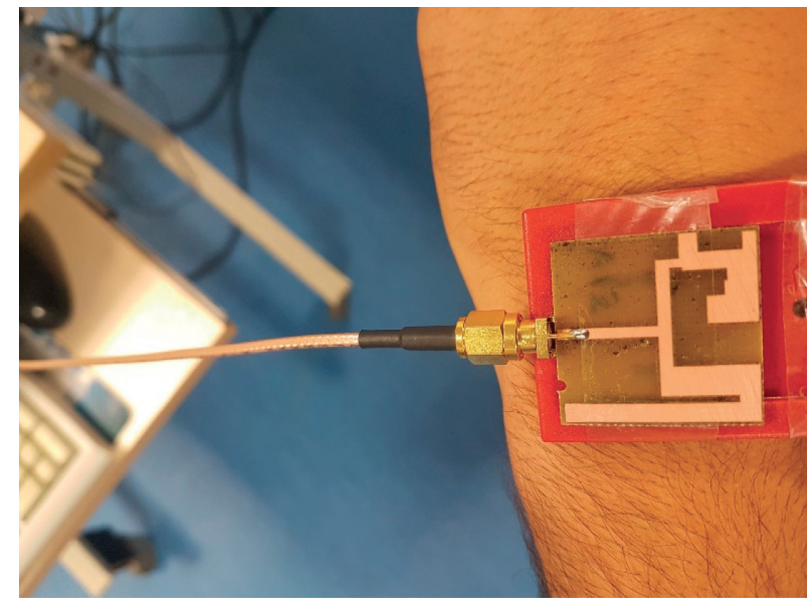

FIGURE 13: Smartwatch case used for S11 measurement.

decrease from the lowest frequency bands to highest frequency bands, up to $19 \%$ in the skin layer, $52 \%$ for the fat layer, $55 \%$ in muscle layer, and $8 \%$ for the bone layer.

The three-dimensional distributions plotted using software CST MWS, of the SAR values $n \mathrm{~W} / \mathrm{kg}$ averaged over a mass of $10 \mathrm{~g}$ calculated over the hand wrist tissue layers are shown in Figure 16. The results are depicted by frequency bands in scope for $2 \mathrm{~mm}$ separation between antenna and hand wrist.
It is worthy to note that the SAR results averaged over $10 \mathrm{~g}$ increase slightly from the skin layer to the fat layer up to $0.009 \mathrm{~W} / \mathrm{Kg}$ and then decrease rapidly from the muscle layer to the bone layer. The values of the SAR averaged over $10 \mathrm{~g}$ are lower in the edges of the wrist than the center due to the antenna position localized in the center top of hand wrist. The obtained results show that the maximum SAR values obtained in each layer of the hand wrist tissue are lower than $4 \mathrm{~W} / \mathrm{kg}$ and respect the SAR limits specified by the FCC Standards. 


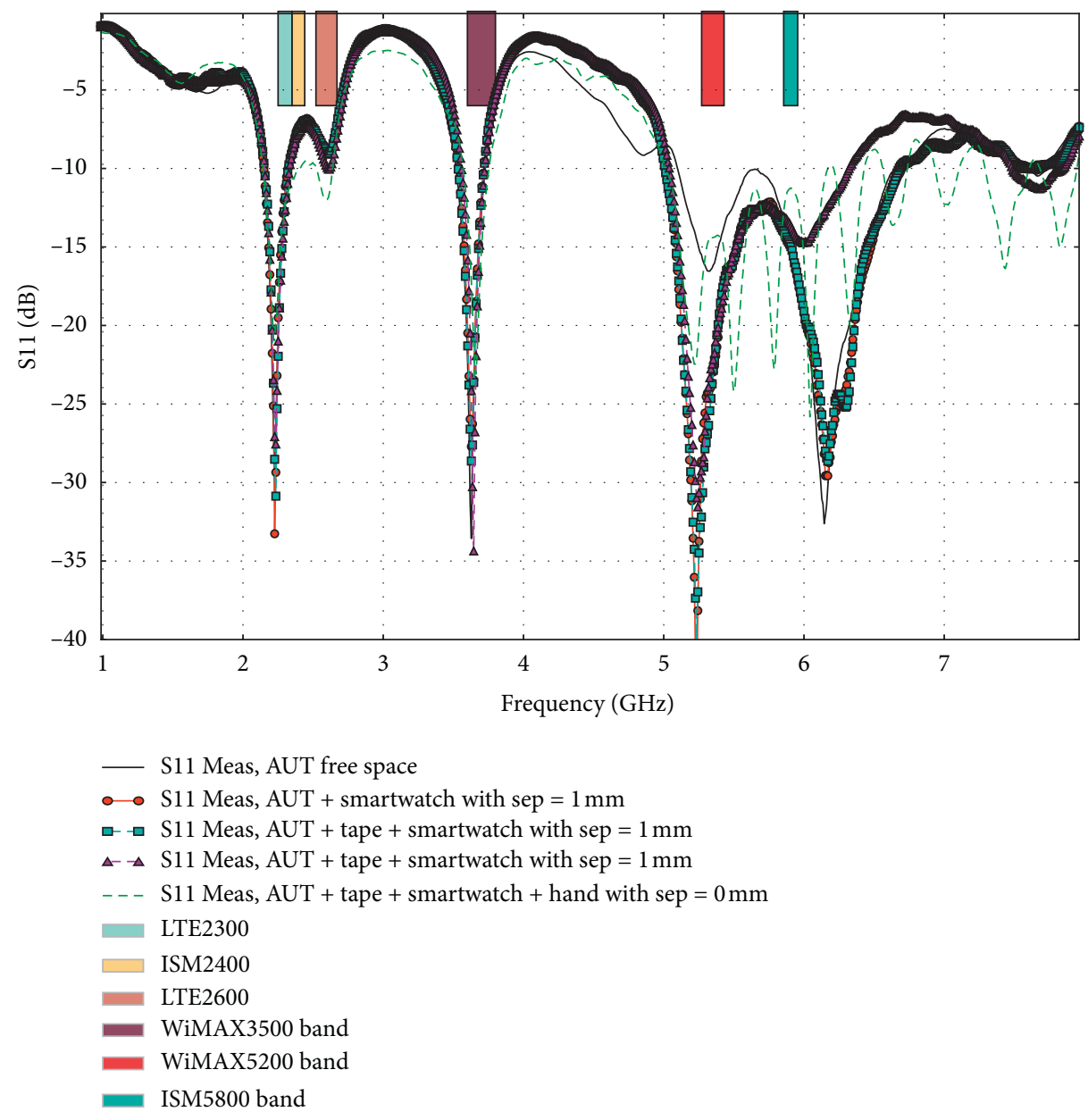

FIGURE 14: Influence of the smartwatch on the antenna S11.

TABle 3: Comparison of the proposed design to state-of-the-art antennas.

\begin{tabular}{|c|c|c|c|c|}
\hline References & Antenna dimension & Covered bands & $\begin{array}{l}\text { Maximum gain } \\
(\mathrm{dBi})\end{array}$ & Smartwatch type \\
\hline [2] & $\begin{array}{l}\text { MIMO: } \\
70 \times 35 \times 0.4 \mathrm{~mm}^{3}\end{array}$ & WiMAX5200, ISM5800 & 4 & Rectangular \\
\hline [3] & $\begin{array}{l}\text { Annular: } \\
\text { diameter: } 42 \mathrm{~mm} \\
\text { height: } 7 \mathrm{~mm}\end{array}$ & ISM2400 & 3.5 & Round \\
\hline [4] & $33 \times 41$ & GPS, WLAN, WiMAX3400 & 3.0 & Rectangular \\
\hline$[14]$ & $31 \times 30$ & ISM2400, WiMAX3500 & 2.25 & $\begin{array}{l}\text { Rectangular, } \\
\text { round }\end{array}$ \\
\hline This work & $29 \times 29 \times 0.8 \mathrm{~mm}^{3}$ & $\begin{array}{l}\text { LTE2300, ISM240, LTE2600, WiMAX3500, WiMAX5200, } \\
\text { ISM5800 }\end{array}$ & 6.9 & $\begin{array}{l}\text { Rectangular, } \\
\text { round }\end{array}$ \\
\hline
\end{tabular}

6.2. Antenna Next to SAM Mouth. The configuration of the antenna next to SAM head mouth provided by CST studio software is shown in Figure 17.

For this scenario the proposed design is localized next to SAM mouth. Three separations between the antenna and SAM mouth are selected: $d=1 \mathrm{~mm}, d=5 \mathrm{~mm}$, and $d=9 \mathrm{~mm}$. The maximum SAR averaged over a mass of $10 \mathrm{~g}$ of the SAM head tissues is calculated at each frequency band and against all separation. Table 6 summarized the maximum SAR results in $\mathrm{W} / \mathrm{Kg}$ calculated using an input power of $125 \mathrm{~mW}$. The obtained results show that the maximum SAR values averaged for $10 \mathrm{~g}$ of the head model tissue decrease up to $71 \%$ when the separation between the antenna and SAM mouth increases with $8 \mathrm{~mm}$. In average the SAR value decreases by $71 \%$ from $d=1 \mathrm{~mm}$ to $d=9 \mathrm{~mm}$. The obtained results clearly confirmed that the maximum SAR values averaged over a mass of $10 \mathrm{~g}$ in SAM Head tissue are below $2 \mathrm{~W} / \mathrm{kg}$ defined by the FCC Standards as SAR limits. 


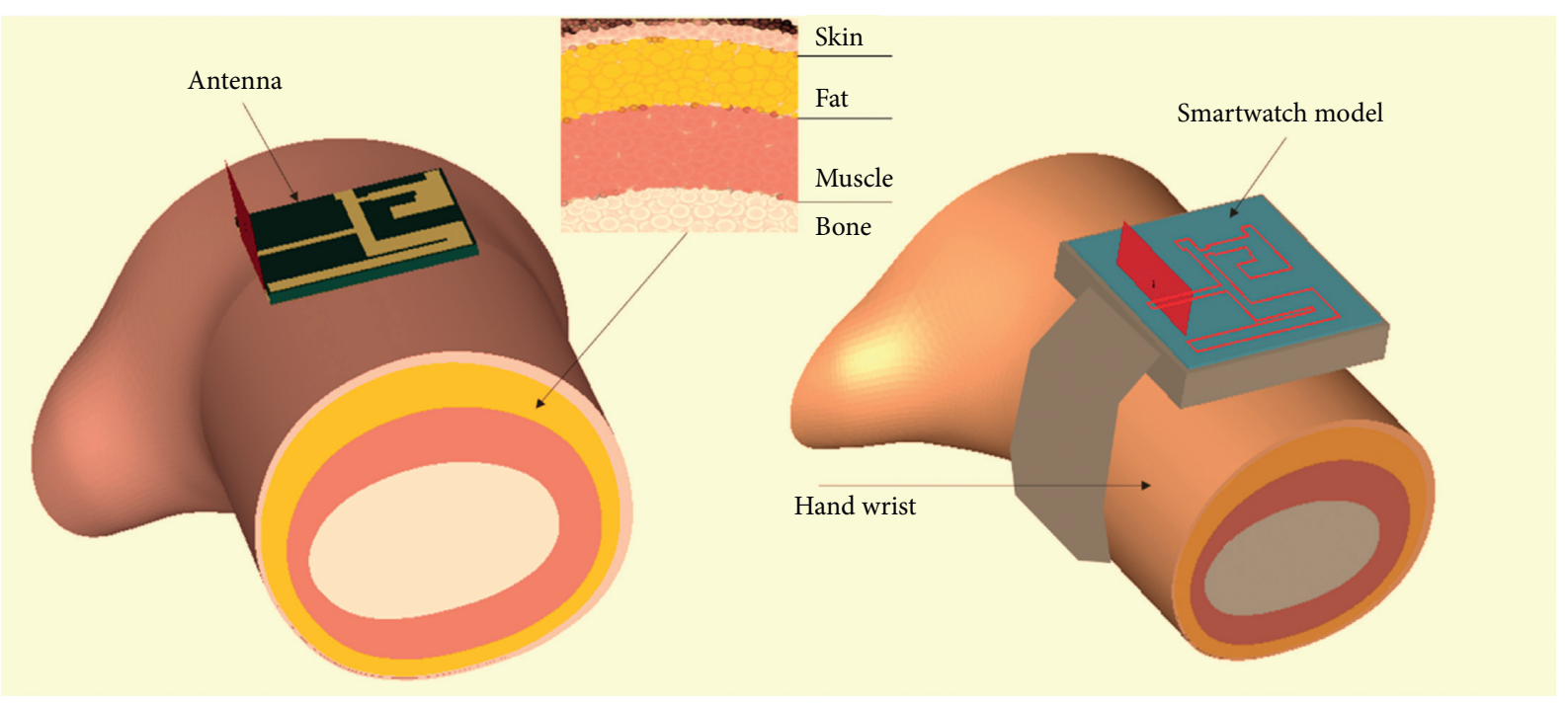

(a)

(b)

FIgURE 15: SAR simulation setup.

TABLE 4: Human hand tissues characteristics [15].

\begin{tabular}{lcccccccccccc}
\hline Frequency $(\mathrm{MHz})$ & \multicolumn{2}{c}{2300} & \multicolumn{2}{c}{2400} & \multicolumn{2}{c}{2600} & \multicolumn{2}{c}{3500} & \multicolumn{2}{c}{5200} & \multicolumn{2}{c}{5800} \\
Tissues & $\varepsilon_{\mathrm{r}}$ & $\sigma(\mathrm{S} / \mathrm{m})$ & $\varepsilon_{\mathrm{r}}$ & $\sigma(\mathrm{S} / \mathrm{m})$ & $\varepsilon_{\mathrm{r}}$ & $\sigma(\mathrm{S} / \mathrm{m})$ & $\varepsilon_{\mathrm{r}}$ & $\sigma(\mathrm{S} / \mathrm{m})$ & $\varepsilon_{\mathrm{r}}$ & $\sigma(\mathrm{S} / \mathrm{m})$ & $\varepsilon_{\mathrm{r}}$ & $\sigma(\mathrm{S} / \mathrm{m})$ \\
\hline Skin & 38.17 & 1.39 & 38.06 & 1.44 & 38.43 & 1.30 & 38.23 & 1.35 & 38.18 & 1.40 & 38.06 & 1.44 \\
Fat & 5.295 & 0.098 & 5.28 & 0.10 & 5.32 & 0.09 & 5.31 & 0.095 & 5.30 & 0.10 & 5.28 & 0.10 \\
Muscle & 54.62 & 1.77 & 54.48 & 1.84 & 54.04 & 1.57 & 53.98 & 1.66 & 53.77 & 1.70 & 53.64 & 1.77 \\
Bone & 18.72 & 0.75 & 18.60 & 0.78 & 15.28 & 0.50 & 15.16 & 0.53 & 15.10 & 0.56 & 15.01 & 0.59 \\
\hline
\end{tabular}

TABLE 5: Maximum SAR results of the antenna mounted on wrist configuration.

\begin{tabular}{|c|c|c|c|c|c|c|}
\hline & Distance & & $d=1 \mathrm{~mm}$ & $d=2 \mathrm{~mm}$ & $d=4 \mathrm{~mm}$ & $d=7 \mathrm{~mm}$ \\
\hline Frequency $(\mathrm{MHz})$ & Tissue & Input power $(\mathrm{W})$ & $10 \mathrm{~g}$ SAR $(\mathrm{W} / \mathrm{kg})$ & $10 \mathrm{~g}$ SAR $(\mathrm{W} / \mathrm{kg})$ & $10 \mathrm{~g}$ SAR $(\mathrm{W} / \mathrm{kg})$ & $10 \mathrm{~g} \mathrm{SAR}(\mathrm{W} / \mathrm{kg})$ \\
\hline \multirow{4}{*}{2300} & Skin & 0.125 & 2.061 & 0.657 & 0.621 & 0.324 \\
\hline & Fat & 0.125 & 2.07 & 0.666 & 0.63 & 0.333 \\
\hline & Muscle & 0.125 & 1.125 & 0.585 & 0.549 & 0.189 \\
\hline & Bone & 0.125 & 0.396 & 0.243 & 0.216 & 0.126 \\
\hline \multirow{4}{*}{2400} & Skin & 0.125 & 2.079 & 0.612 & 0.558 & 0.432 \\
\hline & Fat & 0.125 & 2.088 & 0.621 & 0.567 & 0.441 \\
\hline & Muscle & 0.125 & 1.17 & 0.522 & 0.459 & 0.396 \\
\hline & Bone & 0.125 & 0.288 & 0.216 & 0.189 & 0.135 \\
\hline \multirow{4}{*}{2600} & Skin & 0.125 & 2.349 & 0.81 & 0.612 & 0.378 \\
\hline & Fat & 0.125 & 2.358 & 0.819 & 0.621 & 0.387 \\
\hline & Muscle & 0.125 & 1.89 & 0.747 & 0.486 & 0.369 \\
\hline & Bone & 0.125 & 0.324 & 0.261 & 0.225 & 0.126 \\
\hline \multirow{4}{*}{3500} & Skin & 0.125 & 2.979 & 1.962 & 1.782 & 1.341 \\
\hline & Fat & 0.125 & 2.988 & 1.971 & 1.791 & 1.35 \\
\hline & Muscle & 0.125 & 1.953 & 1.845 & 1.377 & 1.188 \\
\hline & Bone & 0.125 & 0.522 & 0.504 & 0.45 & 0.36 \\
\hline \multirow{4}{*}{5200} & Skin & 0.125 & 3.294 & 3.348 & 2.511 & 1.674 \\
\hline & Fat & 0.125 & 3.303 & 3.357 & 2.52 & 1.683 \\
\hline & Muscle & 0.125 & 2.592 & 3.051 & 2.115 & 1.44 \\
\hline & Bone & 0.125 & 0.36 & 0.459 & 1.944 & 0.27 \\
\hline \multirow{4}{*}{5800} & Skin & 0.125 & 3.15 & 3.033 & 1.953 & 0.774 \\
\hline & Fat & 0.125 & 3.159 & 3.042 & 1.512 & 0.783 \\
\hline & Muscle & 0.125 & 2.538 & 2.619 & 1.377 & 0.693 \\
\hline & Bone & 0.125 & 0.243 & 0.315 & 0.243 & 0.153 \\
\hline
\end{tabular}




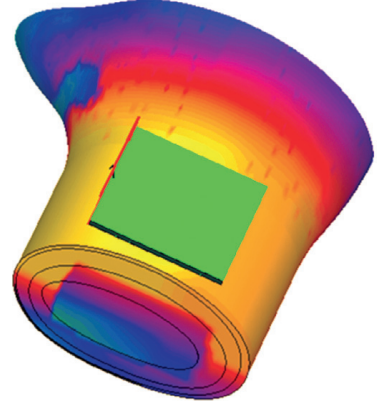

(a)

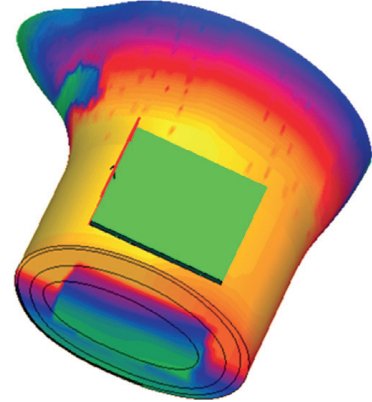

(d)

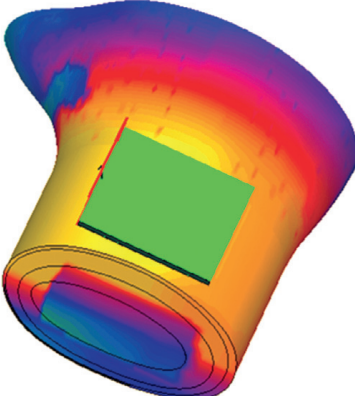

(b)

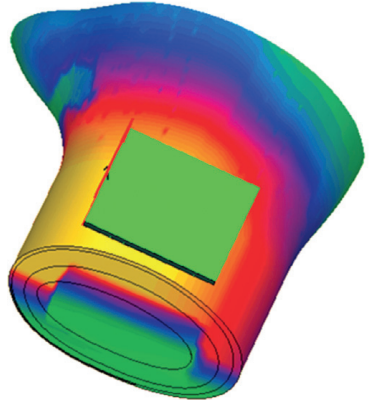

(e)

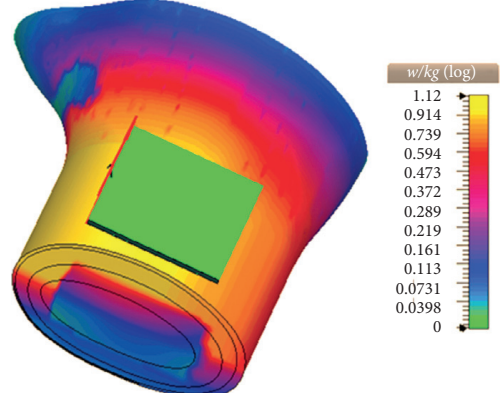

(c)

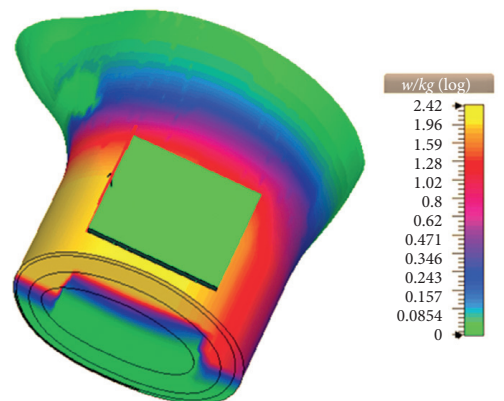

(f)

FIGURE 16: SAR distribution in $\mathrm{W} / \mathrm{kg}$ averaged over $10 \mathrm{~g}$ along hand wrist tissue, for a spacing $d=2 \mathrm{~mm}$. (a) $2.3 \mathrm{GHz}$. (b) $2.4 \mathrm{GHz}$. (c) $2.6 \mathrm{GHz}$. (d) $3.5 \mathrm{GHz}$. (e) $5.2 \mathrm{GHz}$. (f) $5.8 \mathrm{GHz}$.

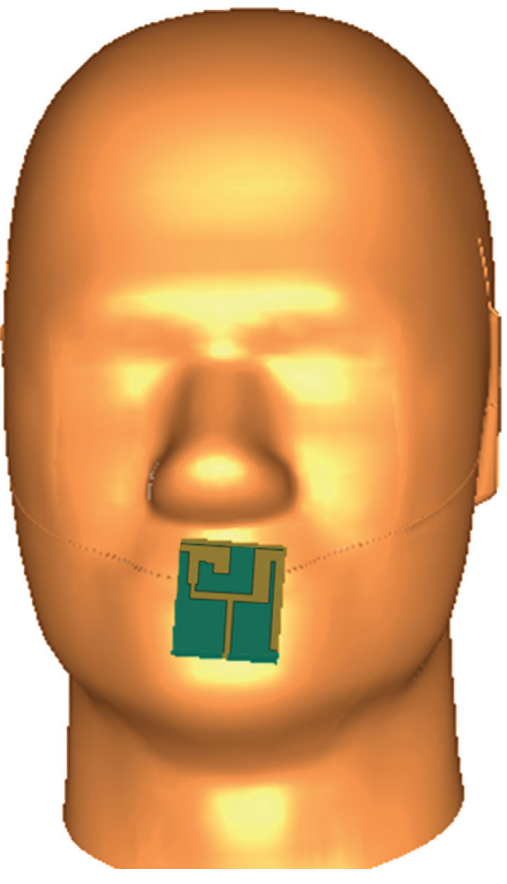

(a)

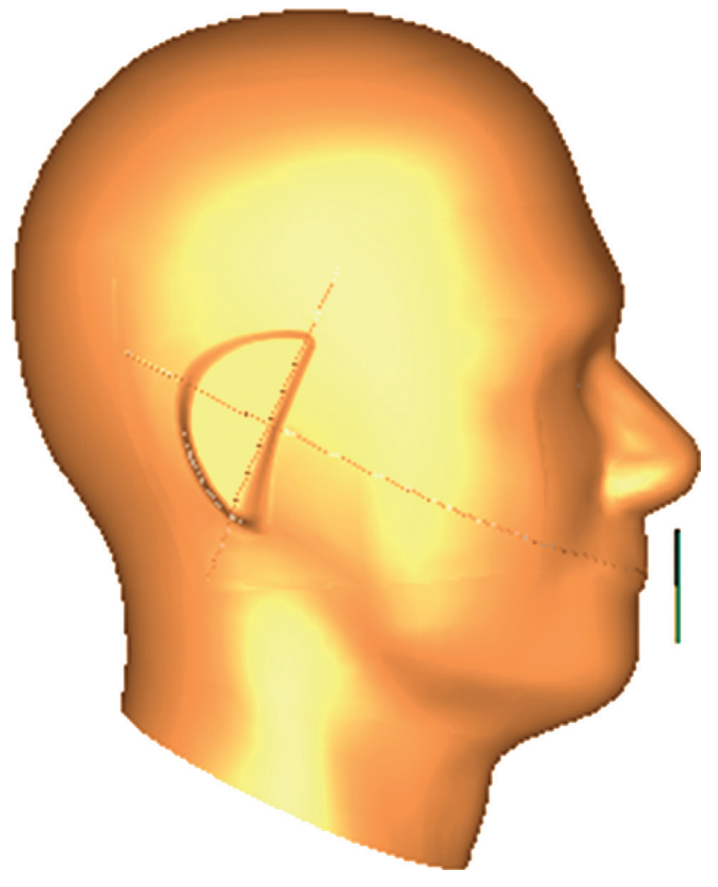

(b)

FIGURE 17: Position of smartwatch antenna next to SAM mouth model.

Figure 18 shows SAR $(\mathrm{W} / \mathrm{kg})$ distribution averaged over $10 \mathrm{~g}$ inside SAM head for an antenna separation to SAM head mouth up to $5 \mathrm{~mm}$. The results of SAR distribution plots are higher with larger impact deep inside SAM head at the frequency bands $2.3 \mathrm{GHz}, 2.4 \mathrm{GHz}$, and $2.6 \mathrm{GHz}$ than the impact presented by frequency bands $3.5 \mathrm{GHz}, 5.2 \mathrm{GHz}$, and $5.8 \mathrm{GHz}$. Based on the results shown in Table 6 and Figure 18, all the values of the SAR averaged over $10 \mathrm{~g}$ inside SAM head obtained at each frequency starting from a separation of $1 \mathrm{~mm}$ are below the SAR limits $2 \mathrm{~W} / \mathrm{kg}$ defined by the FCC standards. 
TABLE 6: Maximum SAR results at each frequency for each distance of antenna next to mouth.

\begin{tabular}{|c|c|c|c|c|c|}
\hline & Distance & & $d=1 \mathrm{~mm}$ & $d=5 \mathrm{~mm}$ & $d=9 \mathrm{~mm}$ \\
\hline Frequency $(\mathrm{MHz})$ & Tissue & Input power $(\mathrm{W})$ & $10 \mathrm{~g}$ SAR $(\mathrm{W} / \mathrm{kg})$ & $10 \mathrm{~g}$ SAR $(\mathrm{W} / \mathrm{kg})$ & $10 \mathrm{~g}$ SAR $(\mathrm{W} / \mathrm{kg})$ \\
\hline 2300 & SAM head & 0.125 & 0.534 & 0.4361 & 0.3115 \\
\hline 2400 & SAM head & 0.125 & 0.6942 & 0.356 & 0.2403 \\
\hline 2600 & SAM head & 0.125 & 0.6764 & 0.3293 & 0.2047 \\
\hline 3500 & SAM head & 0.125 & 1.7622 & 1.0591 & 0.7832 \\
\hline 5200 & SAM head & 0.125 & 1.5931 & 1.068 & 0.5696 \\
\hline 5800 & SAM head & 0.125 & 1.691 & 0.8544 & 0.4895 \\
\hline
\end{tabular}

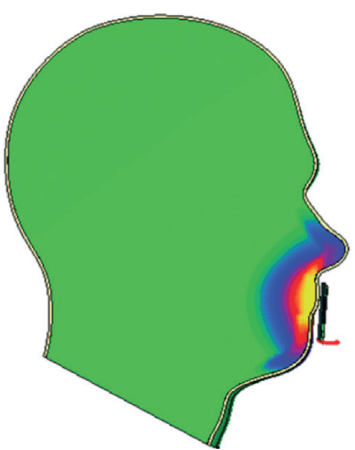

(a)

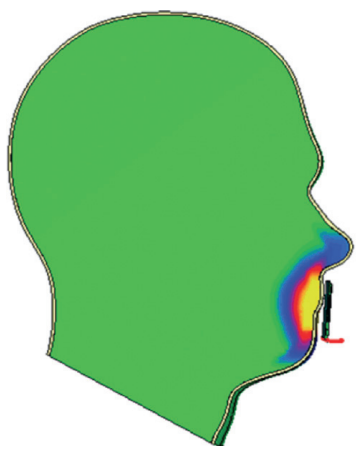

(d)
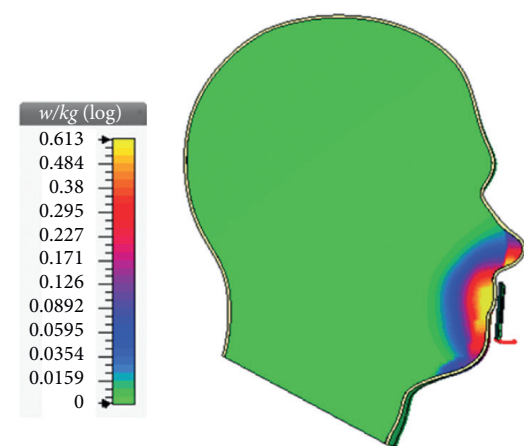

(b)
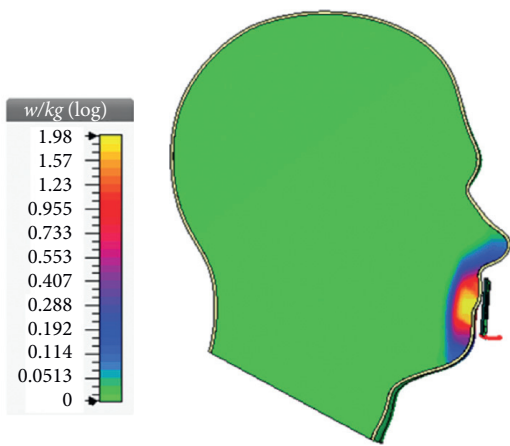

(e)
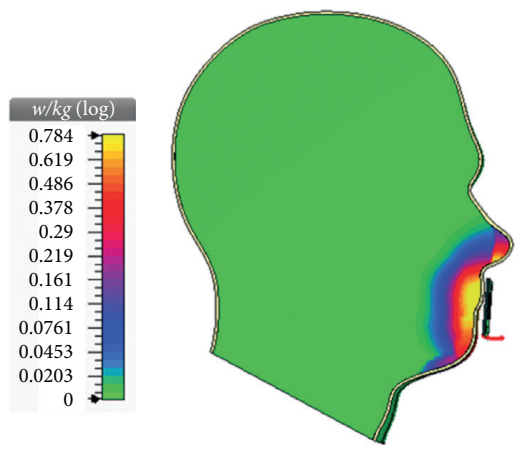

(c)
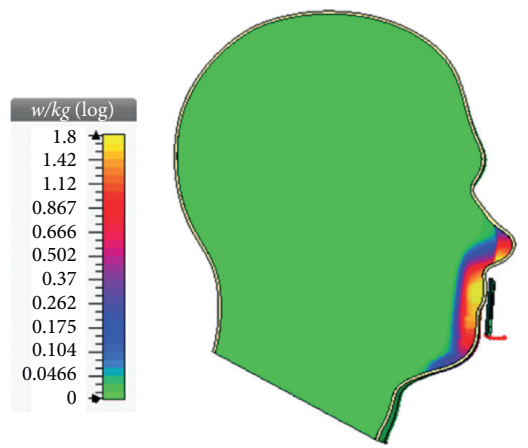

(f)
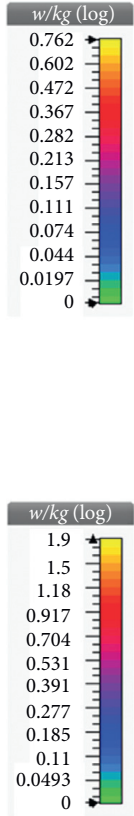

Figure 18: SAR (W/kg) distribution averaged over $10 \mathrm{~g}$ inside SAM head, antenna 5 mm separated to SAM mouth. (a) 2.3 GHz. (b) 2.4 GHz. (c) $2.6 \mathrm{GHz}$. (d) $3.5 \mathrm{GHz}$. (e) $5.2 \mathrm{GHz}$. (f) $5.8 \mathrm{GHz}$.

\section{Conclusions}

This research suggested a novel miniaturized antenna manufactured, tested, and verified for wearable devices use case. The proposed design with its simple low-cost planar structure allows the manufacturer to save considerable amount of money accounting of the number of antennas required in such application worldwide. Comparative to the existing propositions, the presented antenna sizing $29 \times 29 \times 0.8 \mathrm{~mm}^{3}$ is distinguished by its simplicity for manufacturing, ease of deployment inside smartwatches, and excellent performance in terms of radiation pattern, gain, and reflection. The antenna was fabricated and measured in terms of the radiation pattern and the return loss; the results confirm the simulations and show that the antenna is approximately omnidirectional with a maximum gain up to $6.9 \mathrm{dBi}$ and $\mathrm{S} 11$ up to $-25 \mathrm{~dB}$, and it covers all the specified technology bands used in the smartwatch devices such as LTE2300,
ISM2400, LTE2600, WiMAX3500, WiMAX5200, and ISM5800. For the compliance of antenna against the FCC Standards, the SAR averaged for $10 \mathrm{~g}$ of tissue was evaluated for each frequency and for two configuration: antenna on hand wrist model with four tissue layers and antenna next to SAM mouth model. The maximum SAR results obtained starting from a separation of $1 \mathrm{~mm}$ show compliant values below the limit $4 \mathrm{~W} / \mathrm{kg}$ in the case of hand wrist and values below $2 \mathrm{~W} / \mathrm{kg}$ limit in case of SAM head.

\section{Data Availability}

All data can be provided by the authors upon request.

\section{Conflicts of Interest}

The authors declare that they have no conflicts of interest. 


\section{Acknowledgments}

The authors of this work would like to express their great appreciation to Professor Angel Mediavilla from the University of Cantabria for his kind support and assistance.

\section{References}

[1] R. Brunet-Thornton and F. Martinez, Analyzing the Impacts of Industry 4.0 in Modern Business Environments, Vol. 4, IGI Global, Hershey, PA, USA, 2018.

[2] C.-H. Wu, J.-S. Sun, and B.-S. Lu, "Watchstrap-embedded four-element multiple-input-multiple-output antenna design for a smartwatch in $5.2-5.8 \mathrm{GHz}$ wireless applications," International Journal of Antennas and Propagation, vol. 2018, Article ID 1905984, 16 pages, 2018.

[3] D. Wen, Y. Hao, H. Wang, and H. Zhou, "Design of a MIMO antenna with high isolation for smartwatch applications using the theory of characteristic modes," IEEE Transactions on Antennas and Propagation, vol. 67, no. 3, pp. 1437-1447, 2019.

[4] C. Y. Cheung, J. S. M. Yen, and S. W. Y. Mung, "Miniaturized printed inverted-F antenna for internet of things: a design on PCB with a meandering line and shorting strip," International Journal of Antennas and Propagation, vol. 2018, Article ID 5172960, 5 pages, 2018.

[5] B. Fady, A. Tribak, J. Terhzaz, and F. Riouch, "Novel low-cost integrated multiband antenna design customized for smartwatch applications with SAR evaluation," International Journal of Antennas and Propagation, vol. 2020, Article ID 8833839, 14 pages, 2020.

[6] P. Zhou, M. He, Y. Hao, C. Zhang, and Z. Zhang, "Design of a small-size broadband circularly polarized microstrip antenna array," International Journal of Antennas and Propagation, vol. 2018, Article ID 5691561, 10 pages, 2018.

[7] J. M. Jeevani, W. Jayasinghe, and D. Uduwawala, "A novel multiband miniature planar inverted $\mathrm{F}$ antenna design for Bluetooth and WLAN applications," International Journal of Antennas and Propagation, vol. 2015, Article ID 970152, 6 pages, 2015.

[8] S. Niyamanon, R. Senathong, and C. Phongcharoenpanich, "Dual-frequency circularly-polarized truncated square aperture patch antenna with slant strip and L-shaped slot for WLAN applications," International Journal of Antennas and Propagation, vol. 2018, Article ID 970152, 11 pages, 2018.

[9] H. Liu, B. Lu, and L. Li, "Novel miniaturized octaband antenna for LTE smart handset applications," International Journal of Antennas and Propagation, vol. 2015, Article ID 861016, 8 pages, 2015.

[10] M. A. Chung and C. F. Yang, "Built-in antenna design for $2.4 \mathrm{GHz}$ ISM band and GPS operations in a wrist-worn wireless communication device," IET Microwaves, Antennas Propagation, vol. 10, no. 12, pp. 1285-1291, 2016.

[11] B. Wang and S. Yan, "Design of smartwatch integrated antenna with polarization diversity," IEEE Access, vol. 8, p. 1, 2020.

[12] W. Hu, R.-N. Lian, Z.-Y. Tang, and Y.-Z. Yin, "Wideband, low-profile, dual-polarized slot antenna with an AMC surface for wireless communications," International Journal of Antennas and Propagation, vol. 2016, Article ID 7641382, 8 pages, 2016.

[13] "Smartwatches dimensions," 2020, https://www.dimensions. com.

[14] M. M. Hasan Rahman, M. R. I. Faruque, M. T. Islam, and M. U. Khandaker, "Electrically compact SRR-loaded metamaterial inspired quad band antenna for bluetooth/ WiFi/WLAN/WiMAX system," Electronics, vol. 8, no. 7, p. 790, 2019.

[15] May 2020 http://transition.fcc.gov/oet/rfsafety/dielectric. html.

[16] Federal Communications Commission, "Specifc absorption rate (SAR) for cellular telephones," 2012, https://www.fcc.gov/ general/cell-phones-and-specific-absorption-rate.

[17] Federal Communications Commission, Evaluating Compliance with FCC Guidelines for Human Exposure to Radiofrequency Electromagnetic Fields, Federal Communications Commission, Washington, DC, USA, 2001.

[18] International commission on non-ionizing radiation protection, "ICNIRP guidelines: for limiting exposure to timevarying electric, magnetic and electromagnetic fields (up to 300 GHz)," Health Physics, vol. 97, no. 3, 2009.

[19] Federal Communications Commission, "Wireless-devices-andhealth-concerns," August 2018, https://www.fcc.gov/consumers/ guides/wireless-devices-and-health-concerns.

[20] T. Wu, T. S. Rappaport, and C. M. Collins, "The human body and millimeter-wave wireless communication systems: interactions and implications," in Proceedings of the IEEE International Conference on Communications (ICC), London, UK, September 2015.

[21] FCC ID.io, "SAR-test-report-4197534," 2019, https://fccid.io/ 2AHZ7100602018/RF-Exposure-Info/SAR-Test-Report-4197534. 